indicate damage to the muscle and myoneural junction. Such changes do not occur in primary muscle disorders, denervation atrophy, or drug toxicity. ${ }^{2}$ Similar changes at the myoneural junction have, however, been reported in Becker's type of progressive muscular dystrophy. ${ }^{3}$ In the absence of other factors known to precipitate muscle damage our data indicate that isotretinoin may induce reversible damage to skeletal muscle. Since there were no symptoms or signs of damage to the myoneural junction we refrained from performing a study of "iitter" or repetitive nerve stimulation.

We cannot offer an adequate explanation for our findings, although muscle pain and stiffness are features of chronic vitamin A toxicity. ${ }^{4} \mathrm{~A}$ recent experiment showed that retinoic acid given in large doses to pregnant mice modified the phenotype expression of developing muscles in the fetus and increased creatine kinase activity.

We thank Mr Eitan Ben David for his technical help.

Dicken CH. Retinoids: A review. J Am Acad Dermatol 1984;11:541-52

2 Lane RJM, Mastaglia FL. Drug induced myopathies in man. Lancet 1978;ii:562-6.

3 Fukuhara N, Suzuki M, Isubaki T, Kushiro S, Takasawa N. Ultrastructural studies on the neuromuscular junctions of Becker's dystrophy. Acta Neuropathol 1985;66:283-91.

4 Oslon JA. Adverse effects of large doses of vitamin A and retinoids. Semin Oncol 1983;10:290-3.

5 Kwasigroch TE, Skalko RG. Estimation of creatine phosphokinase isoenzrmes: the effects of caffeine and retinoic acid on CPK levels in fetal mouse limbs. Toxicol Lett 1984:21:339-47.

Accepted 21 May 1986

Departments of Dermatology and Neurology, Beilinson Medical Center, Petach Tikva, and the Sackler School of Medicine, Tel Aviv University, Israel

EMMILIA HODAK, MD, resident in dermatology

NATAN GADOTH, $M D$, associate professor in neurology

MICHAEL DAVID, MD, senior lecturer in dermatolog

MIRIAM SANDBANK, MD, professor of dermatology

Correspondence to: Dr Emmilia Hodak, Department of Dermatology, Beilinson Medical Center, Petach Tikva 49100, Israel.

\section{Fish consumption and mortality from coronary heart disease}

An inverse relation between consumption of fish and mortality from coronary heart disease has been found in some recent studies ${ }^{12}$ but not in others. ${ }^{4}$ In a 14 year follow up of 10966 subjects in Sweden we studied the association between fish consumption and mortality from myocardial infarction and from coronary heart disease (including myocardial infarction).

\section{Subjects, methods, and results}

Information on current dietary habits, including fish consumption, was obtained by a self administered questionnaire in $1967-8$ from $15864(75 \%)$ of the
21152 subjects in the population based register of twins born in Sweden from 1886 to 1925 . Each subject's average fish consumption in 1967 was related to his or her total intake of food and classified as high, moderate, low, or no fish consumption. Information on previous cardiovascular symptoms, including angina and myocardial infarction, was also obtained, and all subjects who reported such symptoms were excluded from the study. A link with the records of the Swedish National Cause of Death Register provided information on the year and cause of death for those among the remaining 10966 subjects who died during 1969-82. The number of deaths from myocardial infarction and from coronary heart disease was related to the number of person years at risk during the period of observation. Relative risks for different levels of fish consumption were calculated using people who consumed little or no fish as the reference group. Differences in age and sex distribution were accounted for. ${ }^{5}$ The results in the table show a dose response relation, with the lowest risk for those who had high fish consumption. Sex specific relative risks showed a similar pattern for men and women. Further adjustment was made for smoking habits, relative weight, marital state, geographical region, and degree of urbanisation (information obtained from the previously mentioned questionnaire in 1967-8), and for a history of hypertension (information obtained from a questionnaire in 1963). These adjustments, however, had little or no effect on the relative risks shown in the table.

\section{Comment}

The classification into high, moderate, low, or no fish consumption was peformed in 1967-8 - that is, before the observation period. There were few subjects who never consumed fish, and we therefore had to include subjects with low fish consumption in the "unexposed" group. This mav have led to an underestimation of the strength of the inverse relation between fish consumption and death from myocardial infarction and coronary heart disease. Similarly, the high levels of fish consumption in some earlier studies may account for the apparent lack of effect in these studies.

Kromhout D, Bosschieter EB, Coulander C de $\mathrm{L}$. The inverse relation between fish consumption and 20-vear mortality from coronary heart disease. $N$ Engl 7 .Med 1985;312:1205-9.

2 Shekelle RB, Oglesby P. MacMillan Shrvock A, Stamler J. Fish consumption and mortality from coronary heart disease. N Engl F.Med 1985:313:820.

3 Vollset Sl. Heuch I, Bjelke E. Fish consumption and mortality from coronary heart diseasc. 1 Fngl 7.11ed 1985:313:820-1.

4 Curb Ji), Reed JD. Fish consumption and mortality from coronary heart disease. 1 Fngl 7 . 11 do 1985:313:821.

5 Rothman KJ, Boice JD. Epidemiologic analysis with a programmable calculator. Washington. DC

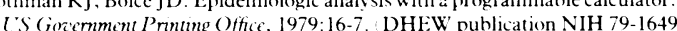

Aciepted 29.May 1986

Department of Epidemiology, National Institute of Environmental Medicine, Box 60208, S-104 01 Stockholm, Sweden

STAFFAN E NORELL, MD, PHD, associate professor ANDERS AHLBOM, PHD, professor

MARIA FEYCHTING, BSC, research assistant

Department of Environmental Hygiene, Karolinska Institute, Box 60400, S-104 01 Stockholm, Sweden

NANCY L PEDERSEN, PHD, researcher

Correspondence to: Dr Norell.

Relative risks of death from coronary heart disease and myocardial infarction in relation to fish consumption of 10966 subjects

\begin{tabular}{|c|c|c|c|c|c|}
\hline \multirow[b]{2}{*}{ Fish consumption } & \multirow{2}{*}{$\begin{array}{l}\text { No of } \\
\text { person vears } \\
\text { at risk }\end{array}$} & \multicolumn{2}{|c|}{ Coronary heart disease } & \multicolumn{2}{|c|}{ Myocardial infarction } \\
\hline & & No of deaths & $\begin{array}{l}\text { Relative risk } \\
(90 \% \text { confidence intervals })\end{array}$ & No of deaths & $\begin{array}{l}\text { Relative risk } \\
(90 \% \text { confidence intervals })\end{array}$ \\
\hline High & 12315 & 69 & $0.85(0.69$ to 1.06$)$ & 28 & $0.70(0.50$ to 0.98$)$ \\
\hline Moderate & 70848 & 373 & $0.94(0.83$ to 1.06$)$ & 184 & $0.91(0.76$ to 1.08$)$ \\
\hline Low & 57084 & 358 & 1.00 & 183 & 1.00 \\
\hline
\end{tabular}

*Adjusted for age and sex. 